\title{
Giant cell arteritis in patients of Indian Subcontinental descent in the UK
}

\author{
N. $\operatorname{Tan}^{1} \cdot$ J. Acheson ${ }^{2} \cdot$ N. Ali $^{1}$
}

Received: 12 February 2018 / Revised: 30 July 2018 / Accepted: 30 August 2018 / Published online: 12 October 2018

(c) The Royal College of Ophthalmologists 2018

\begin{abstract}
Background GCA in the Indian Subcontinent (ISC) is rare. Our centre in London, UK, serves an ethnically diverse population, including a significant population of patients of ISC descent. We hypothesise that patients of ISC descent are no less likely than others to present with symptoms suggestive of GCA and therefore to undergo temporal artery biopsy (TAB). Method A retrospective audit of all TABs performed at our institution over an 8 year period, to identify ethnicity (white, black, ISC, other, unknown) and biopsy result. We compared the proportion of all patients of ISC descent attending the ED to the proportion of ISC patients undergoing TAB. We compared the proportion of positive TABs among ISC patients with positive TABs among white patients. We also compared the proportion of TAB in ISC patients with all non-ISC ethnicities combined.

Results The proportion of patients undergoing TAB who were of ISC descent (16.3\% of 92) was comparable to the proportion of A\&E attendances made up by ISC patients $[p=0.1339] .3 .8 \%(1 / 26)$ of positive biopsies were among patients of ISC descent. White patients were significantly more likely to have a positive biopsy than patients of ISC ethnicity (33\% of 61 white patients vs. $7 \%$ of 15 ISC [ $p=0.0456])$, as were patients of non-ISC ethnicity (32.5\% of 77 non-ISC patients vs. $7 \%$ of 15 ISC patients $[p=0.0464])$.

Discussion At our centre, biopsy proven GCA occurs in patients of ISC descent, but rarely. Full investigation for GCA continues to be appropriate where it is suspected, regardless of ethnicity.
\end{abstract}

\section{Introduction}

Giant cell arteritis (GCA) is an inflammatory vasculopathy that involves the aorta and its large and medium branches. It has a predilection for the branches of the external carotid including the superficial temporal arteries so is also known as temporal arteritis (TA). GCA affecting the ophthalmic arteries may cause sudden and severe impairment of retinal and/or optic nerve perfusion and may lead to profound and permanent visual loss. GCA is a systemic disease which may present acutely or insidiously and which may be life threatening [1].

The incidence and prevalence of GCA has been shown to vary widely across geographical regions. Though relatively

\footnotetext{
N. Tan

n.tan@nhs.net

1 Moorfields Eye Hospital, London, UK

2 National Hospital for Neurology and Neurosurgery, London, UK
}

rare in all populations, evidence strongly suggests the disease is more common in white people [2]. A recent review of the literature shows incidence rates of GCA to vary by country between 1 and 30 per 100,000 population aged $\geq 50$ years [3]. Incidence has been demonstrated to be highest in Scandinavia (20.4-27/10 5 age $\geq 50$ years) $[4-8]$ and in areas with populations of strong Scandinavian descent, including Olmsted County, Minnesota, United States (incidence peaked at $28 / 10^{5} \geq 50$ years in the period 1980-1984) [9] and the United Kingdom (incidence $22 / 10^{5} \geq 50$ years, $95 \%$ CI 21-23 for the period 1990-2001) [10].

GCA is 2-5 times more common in Northern than Southern Europe [11]. Incidence of GCA in Southern Europe, and Israel has been shown to be $6.9-11.3 / 10^{5} \geq 50$ years [12-16]. The population of Otago, New Zealand, has a similarly intermediate incidence of GCA $\left(12.73 / 10^{5}\right.$ for patients $\geq 50$ years) [17]. The largely white population of Saskatoon, Canada, has an incidence of $11.3 / 10^{5}$ for patients $\geq 50$ years [18].

Among non-white populations GCA is less common still. The annual prevalence of GCA in Japan has been calculated 
to be $1.47 / 10^{5} \geq 50$ years [19], compared to $278 / 10^{5}$ (95\% CI 192-268) in the USA [20]. The risk of GCA for people of South-East Asian descent living in the USA has been suggested to be in the order of 20 times less than for white people [21]. The calculated incidence of GCA in Alaska Native patients is very low $\left(1 / 10^{5} \geq 50\right.$ years) [22].

Data for GCA in black people is sparse and findings are contradictory. In Shelby County, Tennessee, USA, Smith showed that in a 10 year study with 26 GCA cases, the incidence in white people was seven times greater than black Americans. Contrastingly, in an 11 year study of GCA in the Texas Gulf Coast, Gonzalez demonstrated that $48 \%$ of 27 patients with "temporal GCA" (not all biopsy proven) were black women, suggesting a proportionally high occurrence of GCA in black female patients.

Hispanic populations in the USA appear to be less commonly affected by GCA than white Americans [23]. Studies of Hispanic populations in Central America have been limited to case reports and so do not give useful information about incidence, other than to suggest rarity [24]. GCA occurs uncommonly in Arab populations and although there is no population-based study to date, incidence is believed to be low [25].

There remains, however, a noticeable paucity of data from other East-Asian, Indian Subcontinent, African and South American populations [3]. Data from the Indian Subcontinent has been limited to case reports and series [26-33]. Sharma et al have combined their own data with the case reports available and report a total of 72 reported cases of GCA in India to date [34]. No formal incidence or prevalence data exist.

We hypothesise that patients of Indian subcontinent descent are no less likely to present with GCA-type symptoms than patients of any other ethnicity, and therefore should be as likely to undergo temporal artery biopsy. Based on the data available, however, we would expect patients of ISC descent to be less likely to have a positive $\mathrm{TAB}$ than patients of other ethnicities.

\section{Methods}

This retrospective study was carried out as part of an audit of TAB results in our institution. This central London eye hospital serves an ethnically diverse population and has a 24-h emergency department to which patients may self-present. The audit was carried out for the period 2006-2014 at Moorfields Eye Hospital, UK. Audit committee approval was granted.

Patients who had undergone TAB were identified through the computerised histopathology reporting database at the Institute of Ophthalmology (EyePath). All patients who had undergone $\mathrm{TAB}$ during the study period were
Table 1 Grouping of NHS ethnicity codes

\begin{tabular}{lll}
\hline Code & Ethnicity & Audit grouping \\
\hline A & British (white) & White \\
B & Irish (white) & White \\
C & Any other white background & White \\
D & White and black Carribean (mixed) & Other \\
E & White and black African (mixed) & Other \\
F & White and Asian (mixed) & Other \\
G & Any other mixed background & Other \\
H & Indian (Asian or Asian British) & Indian Subcontinent \\
J & Pakistani (Asian or Asian British) & Indian Subcontinent \\
K & Bangladeshi (Asian or Asian British) & Indian Subcontinent \\
L & Any other Asian background & Indian Subcontinent \\
$\mathrm{M}$ & Carribean (Black or Black British) & Black \\
$\mathrm{N}$ & African (Black or Black British) & Black \\
$\mathrm{P}$ & Any other Black background & Black \\
$\mathrm{R}$ & Chinese (other ethnic group) & Other \\
$\mathrm{S}$ & Any other ethnic group & Other \\
$\mathrm{Z}$ & Not stated & Unknown \\
$\mathrm{X}$ & Not known & Unknown \\
\hline & &
\end{tabular}

included. A retrospective notes review was carried out of all patients. Data collected included patient age at the time of biospy, gender, laterality of biopsy, ethnicity code (as per NHS ethnicity coding, see Table 1) [http://www.data dictionary.nhs.uk/data_dictionary/attributes/e/end/ethnic_ca tegory_code_de.asp. Accessed 25 May 2015] and biopsy result [35]. Ethnicity information is provided by patients on registration with the NHS or at first presentation to the hospital. For the purposes of this audit, NHS ethnicity codes were grouped into white, black, Indian subcontinent (ISC), other and unknown.

To establish the ethnic make-up of our referral population we examined ethnicity data for all Emergency Department (ED) attendances (any presenting complaint) for a 1 year period.

We compared the proportion of patients of Indian Subcontinent descent attending the ED to the proportion of ISC patients undergoing TAB using $N-1$ Chi Square test. We then compared the proportion of positive TABs in ISC patients with the proportion of positive TABs in white patients. We also compared the proportion of TAB in ISC patients with all non-ISC ethnicities combined using an $N$ -1 Chi Square test $[36,37]$.

\section{Results}

A total of 92 TABs were carried out during the search period. The age range of patients undergoing biopsy was 55-92. Seventy-one percent of patients were female. 
Table 2 Ethnicity distribution of patients attending A\&E compared with ethnicity of patients undergoing TAB

\begin{tabular}{llllll}
\hline Ethnicity group & White & Indian Subcontinent & Black & Other & Unknown \\
\hline Having TAB $(\%) n=92$ & 66.3 & 16.3 & 9.8 & 5.4 & 2.2 \\
$\begin{array}{l}\text { All A\&E attendances } \\
n=46,221(\%)\end{array}$ & 65 & 14 & 12 & 9 & \\
\hline
\end{tabular}

Table 3 Occurrence of positive biopsy by ethnic group

\begin{tabular}{llll}
\hline $\begin{array}{l}\text { Ethnicity } \\
\text { group }\end{array}$ & $\begin{array}{l}\text { Number of } \\
\text { patients } \\
\text { undergoing } \\
\text { biopsy }\end{array}$ & $\begin{array}{l}\text { Number of } \\
\text { patients with } \\
\text { positive } \\
\text { biopsy }\end{array}$ & $\begin{array}{l}\text { Percentage of } \\
\text { ethnic group with } \\
\text { positive biopsy } \\
(\%)\end{array}$ \\
\hline White & 61 & 20 & 33 \\
ISC & 15 & 1 & 7 \\
Black & 9 & 2 & 22 \\
Other & 5 & 2 & 40 \\
Unknown & 2 & 1 & 50 \\
\hline
\end{tabular}

All ethnic groups described in our method were represented in the sample. Of 92 patients undergoing TAB, 61 patients were white, 15 ISC, 9 black, 5 other, 2 unknown.

The ethnic makeup of all patients attending A\&E $(n=$ 46,221 ) was $65 \%$ white, $14 \%$ ISC, $12 \%$ black and $9 \%$ other.

The proportion of patients undergoing $\mathrm{TAB}$ who were of ISC descent (16.3\% of 92) was comparable to the proportion of A\&E attendances made up by ISC patients $[p=$ 0.1339] Table 2.

Of 92 biopsies, 26 biopsies (28\%) showed histopathologic changes consistent with GCA. 63 were negative, 2 were inconclusive with no blood vessel in the biopsy sample (one black patient and one whose ethnicity is unknown). Results for 1 patient were unobtainable.

Of 26 patients with positive biopsies, $20(76 \%)$ were white. $1(4 \%)$ was a patient of ISC descent, $2(8 \%)$ black patients, 2 'other' and 1 'unknown'.

White patients were significantly more likely to have a positive biopsy than patients of ISC ethnicity (33\% of 61 white patients vs. $7 \%$ of 15 ISC $[p=0.0456])$ Table 3. Patients of non-ISC ethnicity (including white, black and 'other') were significantly more likely to have a positive biopsy than ISC patients (32.5\% of 77 non-ISC patients vs. $7 \%$ of 15 ISC patients [ $p=0.0464])$.

Whilst ISC patients were as likely to have symptoms leading to biopsy, they were significantly less likely to have a biopsy positive GCA.

\section{Discussion}

At our London ophthalmic hospital, ISC patients are as likely to present with symptoms leading to the suspicion of GCA as patients of other ethnicities, leading to 15 ISC
Table 41990 Criteria for the classification of giant cell (temporal) arteritis

1. Age at disease onset $\geq 50$ years - Development of symptoms or findings beginning at age 50 or older

2. New headache - New onset of or new type of localised pain in the head

3. Temporal artery abnormality - Temporal artery tenderness to palpation or decreased pulsation, unrelatd to arteriosclerosis of cervical arteries

4. Elevated erythrocyte sedimentation rate - Erythrocyte sedimentation rate $\geq 50 \mathrm{~mm} / \mathrm{h}$ by the Westergren method

5. Abnormal artery biopsy - Biopsy specimen with artery showing vasculitis characterised by a predominance of mononuclear cell infiltration or granulomatous inflammation, usually with multinucleated giant cells

* For purposes of classification, a patient shall be said to have giant cell (temporal) arteritis if at least 3 of these 5 criteria are present. The presence of any 3 or more criteria yields a sensitivity of $93.5 \%$ and a specificity of $91.2 \%$

patients undergoing TAB in an 8 year period. However, in our sample, ISC patients were significantly less likely to be proven to have GCA on biopsy. Only 1 ISC patient in 8 years had biopsy confirmed GCA.

GCA can present a diagnostic challenge and positive TAB forms 1 of 5 American College of Rheumatology criteria for diagnosis (Table 4) [38]. It may be that TAB is a less useful investigation in this population, or that GCA is truly less common. We assume that $\mathrm{TAB}$ is a reliable indicator of GCA in all ethnicities. The presence of GCA is not disputed in patients with positive biopsies but a negative biopsy cannot fully exclude GCA. It may be that TAB has a lower sensitivity in some ethnicities as compared to others.

GCA is known to be uncommon in patients of ISC descent and the literature is limited to case reports and case series. Formal incidence and prevalence data do not exist and are, as is the case with any rare disease, difficult to determine from small numbers. The determinants of the geographic variation in GCA prevalence around remain to be elucidated. It is therefore of interest to study patients of ISC origin living in Europe, as it allows direct comparison with ethnic groups for which we have better prevalence and incidence data.

In terms of ISC patients undergoing TAB, we present a series as big as any series from the ISC literature. Singh and Mathew have published 2 of the largest case series from the 
Indian literature and report 21 and 15 [32, 33] cases of 'confirmed' GCA in Mumbai and South India respectively. Of note only 11/21 patients underwent biopsy in the Singh paper, 10 of which were positive $(90.1 \%)$, suggesting that TAB was not relied upon to arrive at a diagnosis in the presence of clinically suspicious GCA. Mathew describes 15 cases of GCA, 13 of whom underwent TAB with 11 positive results $(84.6 \%)$. Sharma et al present 17 patients with suspected GCA, 13 of whom underwent TAB with a positive biopsy rate of $38.5 \%$ (5/13) [34]. The variation in rate of positive biopsy may be due to difference in threshold for biopsy. In our case, TAB is used as a diagnostic tool in all cases where there is a suspicion of GCA.

Our data echo the literature in demonstrating that GCA is rare-only 26 biopsy proven cases in 8 years-and extremely rare in ISC patients-only 1 patient in 8 years. Previous work that has examined ethnicity of patients with GCA in the UK has echoed our results. Shah and Jain have found that among positive temporal artery biopsies over a 5 year period at Leicester Royal Infirmary, 7.1\% were from patients of ISC descent despite a $30 \%$ ISC population in the area studied [39]. These results closely echo our own. Despite both studies being of small scale, they lend weight to the hypothesis that GCA is very rare in the British ISC population.

Smeeth's 2006 paper examining the incidence of GCA in the UK noted a geographical variation of incidence across the UK, more common in the South East of England, though London itself had a slightly lower incidence of GCA than the surrounding south-eastern counties [10]. Smeeth did not analyse data by ethnicity but attributed variation to unknown, genetic or social factors. Considering our results, further work is needed to establish whether the ethnic makeup of micropopulations across the UK could be a contributing factor to the regional variation of incidence of GCA across the UK.

In any study of race and ethnicity in healthcare, problems can arise in that these terms are not well defined. 'Race' and 'ethnicity' can describe both genetic heritage as well as social and cultural groups. We have intentionally not used the term 'Asian' as this is confusing-in the UK this term is understood to mean of ISC descent, whereas in the USA 'Asian' refers to South East Asian descent. Very limited assumptions about environmental exposure can be made from ethnicity data, particularly in a multicultural city that is home to ethnic populations of multiple generations as well as to recent immigrants.

We have made certain assumptions in our method. We assume that $A \& E$ attendances are a suitable surrogate for understanding the ethnic make-up of our referral population. The strength of making this assumption lies in the large numbers involved-we looked at a sample of 46,221 patients. There is also an underlying assumption that all ethnic groups are as likely as each other to present to A\&E.

We can observe, however, that clinical suspicion of GCA sufficient to merit TAB was as common in ISC patients as patients of other ethnicities. It may be that ISC patients truly have less GCA or that TAB may be less useful in diagnosing GCA in ISC descent patients than in other ethnicities.

Our study is clearly limited by its small scale, but this is inherent in the rarity of GCA in ISC patients. Furthermore, we acknowledge that the patients in this study had sufficient visual symptoms to present to an eye hospital and, consequently, our data may not be repeatable in patients who presented to general hospitals or rheumatology departments or with entirely non-ophthalmic symptoms. It is possible, therefore, that our conclusions may only be relevant to ocular presentations of GCA.

Given that GCA remains a sight and life threatening condition with significant morbidity and mortality, a high index of suspicion remains appropriate [40]. The message from the literature and from our findings is that, although very rare, GCA does occur in patients of ISC descent. We echo Garrity's conclusion that full investigation for GCA continues to be appropriate where it is suspected, regardless of ethnicity [41].

\section{Summary}

\section{What was known before}

- Giant cell arteritis is rare in the Indian Subcontinent and in patients of ISC descent.

\section{What this study adds}

- In our London population, patients of ISC descent were no less likely to present with symptoms of GCA and to undergo TAB than patients of other ethnicities.

- Patients of ISC descent were significantly less likely to have a positive $\mathrm{TAB}$ as compared with other ethnicities.

- Within an 8 year period, 1 patient of ISC descent had a positive TAB. Therefore, although rare, true biopsy proven GCA can be seen in a patient of ISC descent.

- Full investigation for GCA continues to be appropriate, where it is suspected, regardless of ethnicity

\section{Compliance with ethical standards}

Conflict of interest The authors declare that they have no conflict of interest. 


\section{References}

1. Nesher G. The diagnosis and classification of giant cell arteritis. J Autoimmun. 2014;48-49:73-5.

2. Piram M, Maldini C, Mahr A. Effect of race/ethnicity on risk, presentation and course of connective tissue diseases and primary systemic vasculitides. Curr Opin Rheumatol. 2012;24:193-200.

3. Borchers AT, Gerschwin ME. Giant cell arteritis: a review of classification, pathophysiology, geoepidemiology and treatment. Autoimmun Rev. 2012;11:A544-54.

4. Petursdottir H, Johansson E, Nordburg E, Nordburg C. The epidemiology of biopsy-positive giant cell arteritis: special reference to cyclic fluctuations. Rheumatology. 1999;38:1208-12.

5. Haugeberg G, Paulsen PQ, Bie RB. Temporal arteritis in Vest Agder County in Southern Norway: incidence and clinical findings. J Rheumatol. 2000;27:2624-7.

6. Gran JT, Myklebust G. The incidence of polymyalgia rheumatic and temporal arteritis in the county of Aust Agder, south Norway: a prospective study 1987-94. J Rheumatol. 1997;24:1739-43.

7. Elling P, Olsson AT, Elling H. Synchronous variations of the incidence of temporal arteritis and polymyalgia rheuatica indifferent regions of Denmark; association with epidemics of Mycoplasma pneumonia infection. J Rheumatol. 1996;23:112-9.

8. Baldursson O, Steinsson K, Bjornsson J, Lie JT. Giant cell arteritis in Iceland. Arthritis Rheum. 1994;7:1007-12.

9. Salvarini C, Crowson CS, O'Fallon W. Reappraisal of the epidemiology of giant cell arteritis in Olmsted County, Minnesota, over a 50-year period. Arthritis Rheum. 2004;51:264-268.

10. Smeeth L, Cook C, Hall AJ. Incidence of diagnosed polymyalgia rheumatic and temporal arteritis in the United Kingdom 19902001. Ann Rheum Dis. 2006;65:1093-8.

11. Richards BL, March L, Gabriel SE. Epidemiology of large-vessel vasculidities. Best Pract Res Clin Rheumatol. 2010;24:871-83.

12. Gonzalez-Gay MA, Garcia-Porrua C, Rivas M, et al. Epidemiology of biopsy proven giant cell arteritis in northwestern Spain: trend over an18 year period. Ann Rheum Dis. 2001;60:367-71.

13. Gonzalez-Gay MA, Miranda-Filloy JA, Lopez-Diaz MJ, et al. Giant cell arteritis in northwestern Spain: a 25-year epidemiologic study. Medicine. 2007;86:61-8.

14. Salvarini C, Macchioni P, Zizzi F, et al. Epidemiologic and immunogenetic aspects of polymyalgia rheumatic and giant cell arteritis in northern Italy. Arthritis Rheum. 1991;34:351-6.

15. Sonnenblick M, Nesher G, Friedlander Y, et al. Giant cell arteritis in Jerusalem: a 12-year epidemiolical study. $\mathrm{Br} \mathrm{J}$ Rheumatol. 1994;33:938-41.

16. Bas-Lando M, Breuer GS, Berkum Y, Mates M, et al. The incidence of giant cell arteritis in Jerusalem over a 25-year period: annual and seasonal fluctuations. Clin Exp Rheumatol. 2007;25: S15-7.

17. Abdul-Rahman AM, Molteno ACB, Bevin TH. The epidemiology of giant cell arteritis in Otago, New Zealand, a 9 year analysis. $\mathrm{N}$ Z Med J. 2011;124:44-52.

18. Ramstead CL, Patel AD. Giant cell arteritis in a neuroophthalmology clinic in Saskatoon, 1998-2003. Can J Ophthalmol. 2007;42:295-8.

19. Kobayashi S, Yano T, Matsumoto Y, et al. Clinical and epidemiological analysis of giant cell (temporal) arteritis from a nationwide survey in 1998 in Japan: The first governmentsupported nationwide survey. Arthritis Rheum. 2003;49:594-8.
20. Lawrence RC, Felson DT, Helmick CG, et al. Estimates of the prevalence of arthritis and other rheumatic conditions in the United States, Part II. Arthritis Rheum. 2008;58:26-35.

21. Pereira LS, Kwoon MK, Hwang TN, et al. Giant cell arteritis in Asians: a comparative study. Br J Ophthalmol. 2011;95:214-216.

22. Mader TH, Werner RP, Chamberlain DG, et al. Giant cell arteritis in Alaska Natives. Can J Ophthalmol. 2009;44:53-56.

23. Liu NH, LaBree LD, Feldon SE. The epidemiology of giant cell arteritis: a 12 year retrospective study. Ophthalmol. 2001; 108:1145-9.

24. Alba MAA, Mena-Madrazo JA, Reyes E, et al. Giant cell arteritis in Mexican patients. J Clin Rheumatol. 2012;18:1-7.

25. Chaudhry IA, Shamsi FA, Elzaridi E, et al. Epidemiology of giant-cell arteritis in an Arab population: a 22 year study. Br J Ophthalmol. 2007;91:715-18.

26. Desai MC, Vas CJ. Temporal arteritis. The Indian Scene. J Assoc Physicians India. 1989;37:609-11.

27. Kumar R, Gupta H, Jadhav A, Khadilkar S. Bitemporal scalp, lip and tongue necrosis in giant cell arteritis: a rare presentation. Indian J Dermatol. 2013;58:328.

28. Laldinpuii J, Sanchetee P, Borah AL, Ghose M, Borah NC. Giant cell arteritis (temporal arteritis): A report of four cases from north east India. Ann Indian Acad Neurol. 2008;11:185-9.

29. Mucke T, Kesting MR, Holzle F, Wolff K-D. Uncommon presentation of giant cell arteritis: report of two cases with scalp necrosis. Neurol India. 2009;57:61-2.

30. Sood R, Zulfi H, Ray R, Handa R, Wali JP. Giant cell arteritis - a rare cause of fever of unknown origin in India. J Assoc Physicians India. 2002;50:846-8.

31. Vankalakunti M, Dharmanand BG, Chandra S, Pai SA. Giant cell arteritis: a clinical and pathological study. Natl Med J India. 2010;23:18-20.

32. Singh S, Balakrishnan C, Mangat G, Samant R, Bambani M, Kalke S, et al. Giant cell arteritis in Mumbai. J Assoc Physicians India. 2010;58:372-4.

33. Mathew T, Aroor S, Devasia AJ, Mahadevan A, Shobha V, adig $\mathrm{R}$, et al. Temporal arteritis: a case series from South India and an update of the Indian scenario. Ann Indian Acad Neurol. 2012;15:27-30.

34. Sharma A, Sagar V, Prakash M, Gupta V, Khaire N, Pinto B, et al. Giant cell arteritis in India: report from a tertiary care center along with total published experience from India. Neurol India. 2015;63:681-6.

35. NHS ethnicity codes. Accessed 25 May 2015

36. Campbell I. Chi-squared and Fisher-Irwin tests of two-by-two tables with small sample recommendations. Stat Med. 2007;26:3661-75.

37. Richardson JTE. The analysis of $2 \times 2$ contingency tables-Yet again. Stat Med. 2011;30:890.

38. Hunder GG, Bloch DA, Michel BA, Stevens MB, Arend WP, Calabrese LH, et al. The American College of Rheumatology 1990 criteria for the classification of giant cell arteritis. Arthritis Rheum. 1990;33:1122-8.

39. Shah $\mathrm{A}$, Jain $\mathrm{S}$. Ethnic variation in incidence of giant cell arteritis (letter). Br J Ophthalmol. 2008;92:725.

40. De Smit E, Palmer AJ, Hewitt AW. Projected worldwide disease burden from giant cell arteritis by 2050. J Rheumatol. 2015;42:119-25.

41. Garrity ST, Pistilli M, Vaphiades MS, Richards NQ, Subramanian, Rosa PR, et al. Ophthalmic presentation of giant cell arteritis in African-Americans. Eye. 2017;31:113-8. 